\title{
David Weatherall wins the 2010 Lasker Koshland Special Achievement Award in Medical Research for advances in thalassemia
}

I n 1958, David J. Weatherall was a newly qualified physician preparing to enter the British Army for two years of compulsory service; terrified of flying and intimidated by the risks of violent combat and biting snakes, he hoped to serve his term in a hospital on UK soil. Two weeks later, though, he was on a ship bound for Singapore. Despite his trepidation, his experiences there launched not only a remarkable and distinguished research career, but also a new scientific field - molecular medicine. On September 21, Weatherall (Figure 1) will receive the 2010 Lasker Koshland Special Achievement Award in Medical Research, honoring his 50 years of dedication to the research and treatment of hereditary blood disorders.

\section{Hemoglobin: a critical molecule}

Hemoglobin is the oxygen-carrying molecule of the blood. Because oxygen requirements change between embryonic and adult life, the globin genes expressed during embryonic
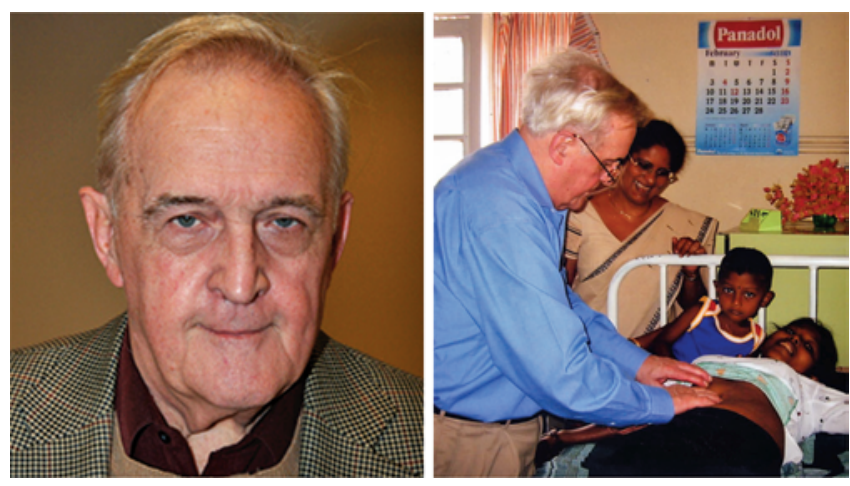

Figure 1

David Weatherall is the recipient of the 2010 Lasker Koshland Special Achievement Award in Medical Research in recognition of his contributions to the molecular understanding and treatment of thalassemia.
Research into these diseases has played a dominant role in shaping our modern understanding of molecular medicine, human genetics, and even anthropology (3).

Thalassemia describes a family of diseases marked by anemia in childhood that is resistant to therapy. First described in the 1920s, thalassemia was initially diagnosed based on the peculiar appearance and decreased fragility of patients' red blood cells $(4,5)$. In the 1950s, analysis by development differ from those expressed in adults and have different affinities for oxygen. A tetrameric molecule, hemoglobin is made up of peptides encoded by different loci that have been given Greek letter designations $-\alpha, \beta, \gamma, \delta$, and $\zeta$. In adults, the primary hemoglobin is hemoglobin A (HbA) (Figure 2), made up of two $\alpha$ chains and two $\beta$ chains, and a smaller fraction is hemoglobin A2 (HbA2), made up of two $\alpha$ and two $\delta$ chains. An exquisitely precise process regulates expression of each of the globin genes during embryonic and fetal development, and the study of these loci has provided a foundation upon which a good deal of the current understanding of blood formation was built (1). Inherited disorders of hemoglobin - the hemoglobinopathies - are among the most common monogenic disorders, and approximately $7 \%$ of the global population are carriers of these alleles (2). electrophoresis had revealed to scientists that thalassemia was related to chemical changes in patients' hemoglobin. Some patients produce a form called $\mathrm{HbH}$, which consists exclusively of $\beta$ chains, and others $\mathrm{Hb}$ Bart, which consists exclusively of $\gamma$ chains. Another form of the disease results from decreased production of the $\beta$ chain and subsequent increased production of the fetal hemoglobin ( $\mathrm{HbF})$, made up of two $\alpha$ and two $\gamma$ chains.

\section{A career-long focus}

Weatherall's first clinical encounter with thalassemia came early in his first year in the army when he met a young patient suffering from severe anemia whose father was a sergeant in the Nepalese regiment. Weatherall had heard of thalassemia in medical school, but at the time it was thought of primarily as a Mediterranean genetic disease. Thus, the diagnosis of hereditary thalassemia in an Asian population was a surprise - and an unwelcome one - as Weatherall's superiors threatened to court-martial him for publishing information about the family of military personnel. As he recalled, "our rather posh head of medicine told me it was bad form to tell the world that one of our top regiments had bad genes." Undeterred, Weatherall continued to pursue his academic interest in thalassemia after being transferred to a hospital in Northern Malaysia the following year. He started to investigate the disease molecularly in his free time, and when his research was hampered by the less-than-ideal conditions of a field hospital, he improvised: "I concocted an electrophoresis machine out of car batteries and some filter paper."

That fascination and singleminded focus persisted after he left the army; he took a fellowship position at Johns Hopkins University. "It turned out there were no thalassemics in Baltimore," said Weatherall, "so to get samples I had to travel up and down the coast on the train." In Baltimore, Weatherall took advantage of a diverse scientific community, interacting with geneticists, hematologists, protein chemists, and biophysicists. It was there that he began a career-long collaboration with the chemist John Clegg, and the two developed a method that allowed the chemical separation of the $\alpha$ and $\beta$ chains of HbA. Eventually, they learned how to quantitatively measure the synthesis rate of each chain. Their work was the first to show that $\alpha$ thalassemia was due to defective production of the $\alpha$ subunit and that $\beta$ thalassemia was due to defective production of the $\beta$ subunit (6). Perhaps more profoundly, Weatherall and Clegg were the first to clearly describe a link between molecular and clinical defects in human disease.

In addition to furthering the molecular understanding of thalassemias, Weatherall's work has contributed to tangible 


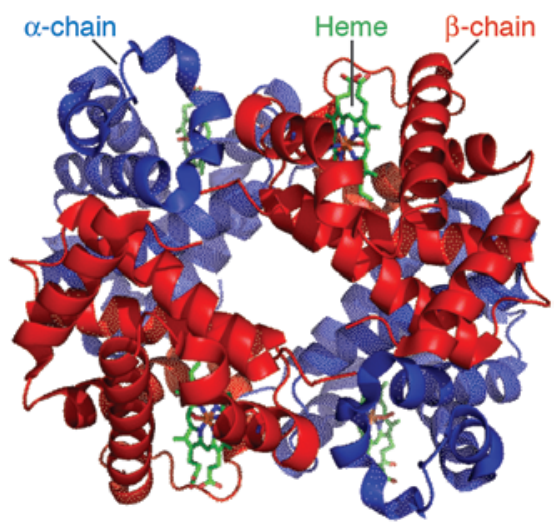

Figure 2

Hemoglobin is a tetrameric molecule that carries oxygen in the blood. In adults, the most common form is $\mathrm{HbA}$, made up of two $\alpha$ globin chains and two $\beta$ globin chains. Adapted from Wikimedia Commons.

advances in clinical treatment. Among the first applications was a test that permitted prenatal diagnosis (7). A few years later, improved DNA technology allowed diagnosis of thalassemia as early as 12 weeks into pregnancy. "That was a nice surprise," remembered Weatherall. "It was curiosity-driven work that within a few years had real clinical implications." Weatherall and colleagues also modified a method of infusion that removes iron buildup from patients to drastically shorten the treatment time (8), a method that remains standard therapy to this day.

\section{Tackling a global health problem}

Although global health agencies often focus their energies on infectious diseases such as malaria and HIV, the worldwide impact of inherited hemoglobinopathies is high. "The numbers are frightening, actually, when you think of the number of children with inherited blood diseases," noted Weatherall. "It is probably about 350,000 new births each year." Given the seriousness of these diseases, this prevalence may seem surprising. However, like carriers of sickle-cell anemia, those with thalassemic mutations tend to be resistant to malaria; thus, these mutations have been maintained in populations with high incidence of the disease. Indeed, thalassemia is most common along the "malaria belt," extending from sub-Saharan Africa and the Mediterranean to India and Southeast Asia (Figure 3 and ref. 3). Interestingly, Weatherall and colleagues showed in the mid-1990s an increased rate of malaria infection in $\alpha$ thalassemics in a Pacific Islander population. Their work suggested that the thalassemic condition might predispose children to infection by the nonlethal parasite Plasmodium vivax and that infection leaves patients with relative immunity to the more malignant strains of the disease (9).

Some of Weatherall's more recent research has explored the global distribution of hemoglobinopathies; for instance sickle-cell anemia is prevalent in sub-Saharan Africa, but rare in Mediterranean populations. He and colleagues have revealed genetic interactions between various alleles that altered their distribution in different populations. Inheritance of both an $\alpha$ thalassemic allele and a sickle-cell allele cancels out the protection provided by inheritance of either individually. Conversely, some populations maintain high frequencies of both $\alpha$ and $\beta$ thalassemia alleles; inheritance of both of these ameliorates the clinical deficiencies of inheriting either, while malaria resistance is maintained (10).

Weatherall's work has demonstrated that in addition to the selective advantage of malaria resistance, there are other factors that maintain a high frequency of thalassemic alleles. In many of the most affected populations, consanguinuity is common. This genetic isolation can keep deleterious alleles present that would otherwise be lost from a more outbred population. In addition, as sanitation and health care conditions improve in developing nations, affected individuals who might have perished in childhood survive to diagnosis and, increasingly, to reproductive age (11).

Since the 1970s, Weatherall has collaborated with the World Health Organization in the fight against thalassemia at a global level. To help spread diagnosis and treatment knowledge, Weatherall has been instrumental in setting up collaborations between wealthy countries and the developing world - so-called "north-south" partnerships. These interactions provide training for the diagnosis and management of the disease, support primary research, and also promote fund raising for the building of new treatment and diagnosis centers. Recently, Weatherall has publicly advocated establishing "south-south" partnerships, funding connections between two developing nations that might have differing levels of knowledge and expertise. "The message I'm trying to get out is that these partnerships are a very cost-effective way to address disease," explained Weatherall. "I'm trying to persuade our government that rather than pouring money into these countries willynilly to give them these partnerships."

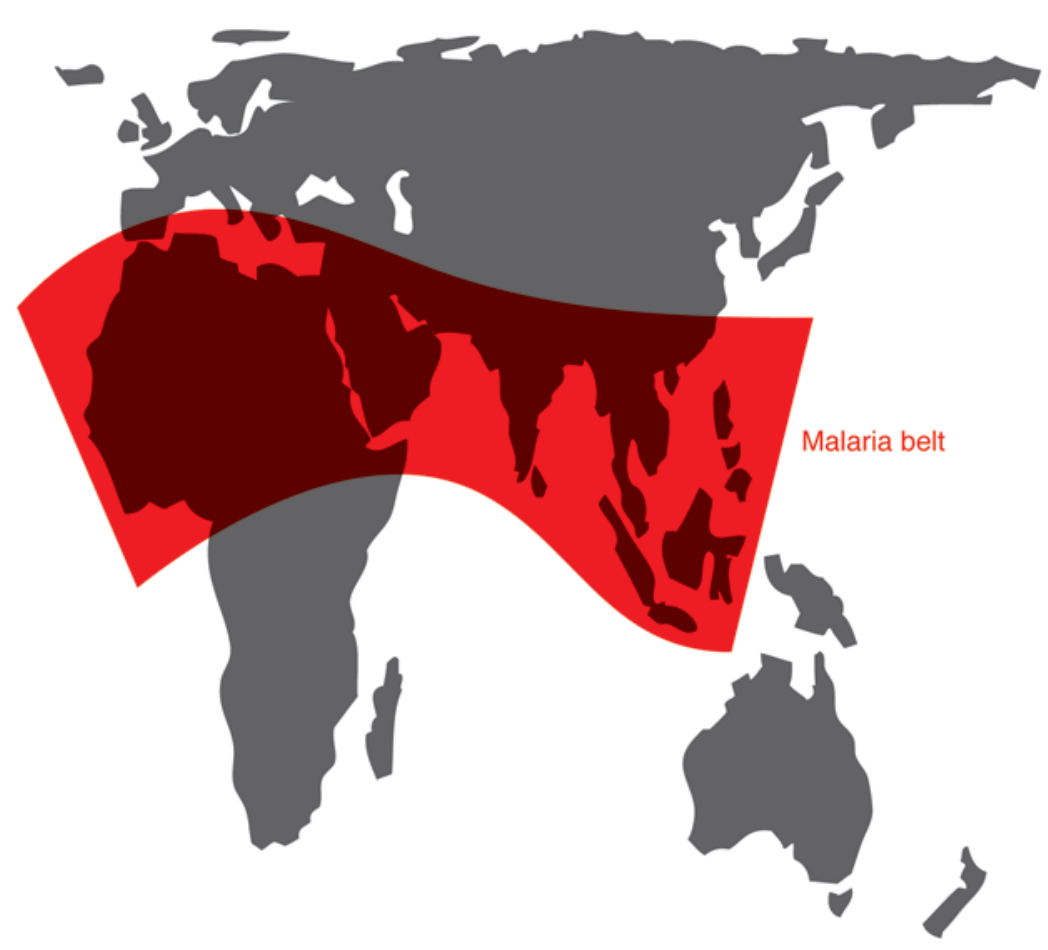

Figure 3

Thalassemia is most common in the "malaria belt" - a region spanning the Mediterranean, Africa, and Southeast Asia. 


\section{Pioneering science: the making of molecular medicine}

Weatherall's research career spanned a period of rapid and dramatic advancement in molecular biology. As he remembers, "In the late '60s and early '70s, when looking at protein synthesis, you could make some guesses about what was happening at the molecular level. Surprisingly, in two or three cases you were able to anticipate what the molecular defect was likely to be." Weatherall and his collaborators took advantage of the developing DNA technology in the 1970s and applied it to the problem of thalassemia; eventually they were able to sequence and identify the mutations that resulted in various forms of the disease. Indeed, thalassemia mutations were among the first molecular defects described at the DNA level.

The understanding of thalassemia that resulted from this work has been a model for the field of molecular medicine as a whole. As more mutations have been sequenced and more patients identified, Weatherall has been struck both by the diversity of genetic defects that can result in disease phenotype and by the clinical heterogeneity that can spring from a single genetic mutation: "Now everyone is looking at the genetic components of diabetes and heart disease... I think what the thalassemias have taught us is that even the simplest genetic diseases are not so simple." Indeed, Weatherall believes that a more complete understanding of clinical heterogeneity is a key to cost-effective management of thalassemia as a global health problem. Currently, many patients undergo regular transfusions throughout their lives, though the severity of their dis- ease may not actually merit such aggressive treatment. Molecular diagnosis and a better grasp of genotype-phenotype relationships might more accurately predict the ideal therapy for each patient and dramatically reduce such waste (12).

In an effort to promote research that uses molecular approaches to address medical questions, Weatherall founded the Institute of Molecular Medicine at Oxford University in 1989. Weatherall explained that in the 1980s, "particularly in the UK, there was nowhere for a young medic to be trained in molecular technology in an atmosphere where it was being applied to medical questions. And similarly a young PhD who wanted to apply that kind of research in the medical direction - there was no place where that was happening... We generated an atmosphere where that kind of training could take place." The institute, renamed the Weatherall Institute for Molecular Medicine after his retirement in 2000, has become an international leader in biomedical research.

\section{Lasting dedication and vision for the future}

As for the way forward in the fight against thalassemia, though he supports innovative research and looks forward to the application of new technologies, Weatherall advocates a more simple and straightforward approach to management of the disease in the developing world. "There are two aspects to the future, obviously: prevention or symptomatic treatment ... I think it's crazy to say we're just going to correct these diseases. We've been saying for twenty years that gene therapy is just around the corner - well, it's a long corner.”
Though he officially retired a decade ago, Weatherall continues to contribute to the field, authoring almost a dozen articles in just the last two years. But even as his accomplishments over the last half century are recognized by the Lasker Koshland Special Achievement Award in Medical Research, his attitude might best be described as humble: "I'm just hoping my friends will tell me to stop research when I'm making a fool of myself."

\section{Kathryn Claiborn}

1. Weatherall DJ, Clegg JB. Recent developments in the molecular genetics of human hemoglobin. Cell. 1979;16(3):467-479.

2. Higgs DR, Weatherall DJ. The alpha thalassemias. Cell Mol Life Sci. 2009;66(7):1154-1162.

3. Pollitzer W. Hemoglobins, haptoglobins, and transferrins in man. Am Anthropol. 1963;65(6):1295-1313.

4. Cooley TB, Lee P. Series of cases of splenomegaly in children with anemia and peculiar bone changes. Trans Amer Pediat Soc. 1925;37:29.

5. Neel J, Valentine W. Further studies on the genetics of thalassemia. Genetics. 1947;32(1):38-63.

6. Weatherall DJ, Clegg JB, Naughton MA. Globin synthesis in thalassemia: an in vitro study. Nature. 1965;208(5015):1061-1065.

7. Fairweather DV, et al. Antenatal diagnosis of thalassemia major. Br Med J. 1980;280(6228):1347-1350.

8. Pippard MJ, Callender ST, Weatherall DJ. Intensive iron-chelation therapy with desferrioxamine in iron-loading anemias. Clin Sci Mol Med. 1978; 54(1):99-106.

9. Williams TN, et al. High incidence of malaria in alpha-thalassemic children. Nature. 1996; 383(6600):522-525.

10. Penman BS, Pybus OG, Weatherall DJ, Gupta S. Epistatic interactions between genetic disorders of hemoglobin can explain why the sickle-cell gene is uncommon in the Mediterranean. Proc Natl Acad Sci US A. 2009;106(50):21242-21246.

11 . Weatherall DJ. Thalassemia as a global health problem: recent progress toward its control in the developing countries. Ann N Y Acad Sci. 2010;1202:17-23.

12. Weatherall DJ. Phenotype-genotype relationships in monogenic disease: lessons from the thalassemias. Nat Rev Genet. 2001;2(4):245-255. 